\title{
Cantons de Roulans, Marchaux, Besançon sud,
} Besançon nord

Prospection inventaire (2001)

Florian Bourguet

\section{(2) OpenEdition \\ Journals}

Édition électronique

URL : https://journals.openedition.org/adlfi/8531

ISSN : 2114-0502

Éditeur

Ministère de la Culture

Référence électronique

Florian Bourguet, «Cantons de Roulans, Marchaux, Besançon sud, Besançon nord » [notice

archéologique], ADLFI. Archéologie de la France - Informations [En ligne], Bourgogne-Franche-Comté, mis en ligne le 01 mars 2001, consulté le 28 juillet 2021. URL : http://journals.openedition.org/adlfi/8531

Ce document a été généré automatiquement le 28 juillet 2021.

(c) ministère de la Culture et de la Communication, CNRS 


\section{Cantons de Roulans, Marchaux, Besançon sud, Besançon nord}

Prospection inventaire (2001)

Florian Bourguet 
1 Parallèlement à un diplôme universitaire consacré à un inventaire archéologique sur la vallée du Doubs entre Besançon et Baume-les-Dames, des prospections ont été effectuées afin de mieux cerner le potentiel archéologique de ce secteur.

Outre quelques sites préhistoriques nouveaux repérés sur le premier plateau (communes de Gennes, Saône, Vauchamps, Nancray et Osse), la zone de découverte principale se situe en amont de Besançon, au niveau des villages de Chalezeule et de Thise.

3 Ce secteur apparaît comme très important au vu de la densité du matériel découvert. Deux sites majeurs étaient déjà connus des services de la carte archéologique : les zones à l'est et à l'ouest de l'aérodrome (Trébignon). Il faut maintenant ajouter l'ensemble de l'actuelle zone industrielle. Les découvertes concernant la Préhistoire se sont révélées nombreuses et intéressantes, car elles concernent plusieurs périodes.

4 Une lamelle de l'Épipaléolithique, des fragments de hache en roche verte, une belle lame de faucille en silex du Grand Pressigny, des pointes de flèches, dont une à pédoncule et ailerons du Néolithique final, deux racloirs du Paléolithique moyen et des outils mésolithiques, etc.

5 Ces quelques exemples montrent l'importance de cette vaste zone de colline située entre Thise et Besançon. Les principales périodes représentées sont le Mésolithique et le Néolithique, mais des traces montrent une possible occupation antérieure (Épipaléolithique, etc.).

6 Les prospections menées sur d'autres villages en amont ne montrent pas une occupation humaine aussi importante lorsqu'on analyse le matériel retrouvé, ce qui laisse penser que le secteur de Thise occupait une place importante au niveau local durant les périodes préhistoriques. Cela peut être expliqué par un milieu plus favorable (zone ouverte) et la proximité de cours d'eau (Doubs et ruisseau de Trébignon). 


\section{INDEX}

nature https://ark.frantiq.fr/ark:/26678/crtBhWSZf1tw8

chronologie https://ark.frantiq.fr/ark:/26678/pcrtwpx5MU2hlw, https://ark.frantiq.fr/ark:/ 26678/pcrtFS9v4PxyYL, https://ark.frantiq.fr/ark:/26678/pcrtT7uGEJ3s0j, https://ark.frantiq.fr/ ark:/26678/pcrtNcvU9Ed8ln, https://ark.frantiq.fr/ark:/26678/pcrtNs85SfBRuH, https:// ark.frantiq.fr/ark:/26678/pcrtH8P95EucZz, https://ark.frantiq.fr/ark:/26678/pcrtkWTHVxnZWN lieux https://ark.frantiq.fr/ark:/26678/pcrtSEeAipsBlD, https://ark.frantiq.fr/ark:/26678/ crtWHH6M7PQ5w, https://ark.frantiq.fr/ark:/26678/pcrt4WJj7TRcto, https://ark.frantiq.fr/ ark:/26678/pcrtys3dG7sOWx, https://ark.frantiq.fr/ark:/26678/pcrty7NcblG5qk, https:// ark.frantiq.fr/ark:/26678/pcrtAFrj8P55jZ, https://ark.frantiq.fr/ark:/26678/pcrtV181LwUJ2g, https://ark.frantiq.fr/ark:/26678/pcrtcUpmeIlki4, https://ark.frantiq.fr/ark:/26678/ pcrttmLjOuyCw1, https://ark.frantiq.fr/ark:/26678/pcrtBsWBQKeqjU, https://ark.frantiq.fr/ ark:/26678/pcrtHGEdaDVSpc

Année de l'opération : 2001

sujets https://ark.frantiq.fr/ark:/26678/pcrtuDGmtyntVb, https://ark.frantiq.fr/ark:/26678/ pcrtgi6nA8qPOv, https://ark.frantiq.fr/ark:/26678/pcrtNLITkP6OLz, https://ark.frantiq.fr/ark:/ 26678/pcrtxs8Kml8jLw, https://ark.frantiq.fr/ark:/26678/pcrtI9ADjL6wEs, https:// ark.frantiq.fr/ark:/26678/pcrtYdJwXpuL9x, https://ark.frantiq.fr/ark:/26678/pcrtrugvfgLj8m, https://ark.frantiq.fr/ark:/26678/pcrtDMPItSUxPY, https://ark.frantiq.fr/ark:/26678/ pcrtwnX03Ud8U5, https://ark.frantiq.fr/ark:/26678/pcrt5L4aRNkptl, https://ark.frantiq.fr/ ark:/26678/pcrtfyWGSYTyS1, https://ark.frantiq.fr/ark:/26678/pcrtd79H4ej2zN, https:// ark.frantiq.fr/ark:/26678/pcrtmDqe8H6RNF, https://ark.frantiq.fr/ark:/26678/pcrtcImHZKlBce, https://ark.frantiq.fr/ark:/26678/pcrtRNmXmLw95p, https://ark.frantiq.fr/ark:/26678/ pcrtKJVpuP3AET, https://ark.frantiq.fr/ark:/26678/pcrtDlzbGxWvTo, https://ark.frantiq.fr/ ark:/26678/pcrtbptj4SOA1W, https://ark.frantiq.fr/ark:/26678/pcrthXosl9QxQ2, https:// ark.frantiq.fr/ark:/26678/pcrtfhnY18Qz3w 